\title{
SOCIO-ENVIRONMENTAL FACTORS IMPACTING ON TEACHERS' ATTITUDES TOWARDS CODE-SWITCHING IN ESL CLASSROOMS IN A RURAL DISTRICT IN MALAYSIA
}

\section{Tan Nam Siong ${ }^{1,2}$ and Low Hui Min ${ }^{1 *}$}

${ }^{1}$ School of Educational Studies, Universiti Sains Malaysia, Pulau Pinang, MALAYSIA

${ }^{2}$ Bin Sin Primary School, Perak, MALAYSIA

*Corresponding author: lowhm@usm.my

Published online: 25 September 2017

To cite this article: Tan, N. S. and Low, H. M. 2017. Socio-environmental factors impacting on teachers' attitudes towards code-switching in ESL classrooms in a rural district in Malaysia. Kajian Malaysia 35(2): 105-125. https://doi.org/10.21315/km2017.35.2.6

To link to this article: https://doi.org/10.21315/km2017.35.2.6

\begin{abstract}
Code-switching is common in certain English as Second Language (ESL) classrooms in Malaysia. In this study, a survey method was used to account for the impacts of macro-level socio-environmental factors such as school type, school size and class size on ESL teachers' attitudes towards classroom codeswitching. The results showed that in general, teachers reported positive attitudes towards classroom code-switching in relation to teachers' persona, subject access, classroom management and interpersonal relationships. Correlation and regression analyses showed that teaching experience was a significant predictor of teachers' attitudes towards classroom code-switching in relation to teachers' persona; while the matching of teachers' and students' ethnicity was a significant predictor of teachers' attitudes towards classroom code-switching in relation to interpersonal relationships. The findings contributed the insights that different socio-environmental factors provided explanations for different aspects of teachers' attitudes towards classroom code-switching. The interplay of factors affecting teachers' attitudes on classroom code-switching is multidimensional and should only be interpreted by considering all possible factors involved.
\end{abstract}

Keywords: code-switching, ESL teachers, teachers' attitude, socio-environmental factors 


\section{INTRODUCTION}

\section{Classroom Code-Switching}

Classroom code-switching has been widely investigated in the past three to four decades (Lin, 2013). The general term of "code-switching" refers to the exchange of two sets of linguistic units in non-ambiguous, reversible, and contextually-free manners (Lin, 2013, with reference to the definition of 'code' in Alvarez-Caccamo, 2001). Milroy and Muysken (1995) defined code-switching as the alternative use of two or more languages in the same conversation. Code-switching can occur in three different conditions within a conversation, namely changes of codes between the turns, between the utterances within a single turn, or within a single utterance (Milroy and Muysken, 1995; Poplack, 1980; Romaine, 1997). When code-switching occurs, the contrast between one code and the other is meaningful, and it can be interpreted by the conversation partners (Auer, 1999). Hence, codeswitching is often described as a strategy used by bi- or multilinguals to serve certain pragmatic functions (Auer, 1999; Holmes, 2001). For example, a bilingual speaker might use code-switching as a strategy to express solidarity, assert social status, quote someone or a proverb, add emphasis, add authority, or express feelings (Holmes, 2001).

Due to the variations in the types and functions of code-switching, several terms have been used by linguists and applied linguists to refer to the acts of using more than one language in conversation, including "language mixing" (Pfaff, 1979), "code meshing" (Michael-Luna and Canagarajah, 2008), "translanguaging" (Creese and Blackledge, 2010; Palmer et al., 2014) and "fused lect" (Auer, 1999). In this paper, classroom code-switching is used as a general term to refer to the practice of using more than one language in classroom conversations. The notion of code-switching used in this study covers a range of bi- and multilingual conversational practices as illustrated by the terms outlined above. Specifically, the investigation focused on classroom code-switching from the perspective of English as Second Language (henceforth, ESL) teachers.

ESL teachers in many parts of the world have been found to use codeswitching as a teaching pedagogy to teach English to ESL learners. Different taxonomies of classroom code-switching functions have been put forward by biand multilingual researchers (Ferguson, 2006; 2009; Lin, 2013), predominantly based on the theory of socio-semiotics introduced by Halliday (1978). According to Halliday, the choice of language codes is believed to be driven by the ideational, interpersonal and textual functions of linguistic communication within specific social systems. By considering both the pedagogical and interpersonal functions of classroom code-switching, Ferguson $(2006 ; 2009)$ identified three broad categories of classroom code-switching functions, namely (1) knowledge construction and transmission, (2) classroom management, and (3) interpersonal relations. 
The function of knowledge construction and transmission is related to the ideational and textual functions in the socio-semiotic model (Halliday, 1978). The ideational function is related to the use of code-switching by teachers in order to utilise the students' existing knowledge in their first languages. This function is very much related to making reference to the students' existing life experience in order to help them to make sense of the learning of new vocabulary and concepts in the lesson (Lin, 2013). On the other hand, the textual function is related to how the meanings generated from the ideational function are realised to attain the desired functional communication within the socio-semiotic system. In the ESL classrooms, these two functions provide the rationale to explain the relative advantage of using the students' first language to learn English. When ESL teachers code-switch to the students' first language in teaching English, it is possible that the teachers are able transmit the novel information to the students more effectively and to ultimately produce a better ESL learning outcome.

For example, Ramachandran and Abdul Rahim (2004) investigated the application of the translation method in teaching vocabulary to a sample of elementary school ESL students in Malaysia. They found that the translation method, i.e., the pedagogy of utilising the first language word equivalents in teaching new English vocabulary had positive effects on the students' vocabulary recall and retention. A similar outcome was found by Joyce (2015) in a study which involved English as Foreign Language (EFL) undergraduate students in Japan. These empirical evidences supported the notion that classroom code-switching could contribute to knowledge construction and transmission in the ESL and EFL classrooms (refer to a review by Ghobadi and Ghasemi, 2015).

The functions of classroom management and interpersonal relations proposed by Ferguson $(2006 ; 2009)$ are related to the use of code-switching by teachers and students to negotiate and to achieve the desired social distances. As explained by Ferguson $(2006 ; 2009)$, classroom management is more about the shift of footing from lesson content to discipline control while the function of interpersonal relations is more about the humanisation of the classroom climate. Hence, Ferguson's $(2006 ; 2009)$ taxonomy is hierarchical in nature which covers a more formal function of classroom code-switching (namely, subject access) to less formal functions (namely, classroom management and interpersonal relations). From the constructivist's perspective, these three code-switching functions could also be interpreted based on cognitive and affective needs of the students (Probyn, 2009).

In a classroom code-switching study in China, Yao (2011) developed a questionnaire that investigated the four functions of code-switching in ESL classrooms. The questionnaire contained 20 items related to the four functions of code-switching, namely teachers' persona, subject access, classroom management and code-switching for interpersonal relations. Yao (2011) found, using the 
questionnaire, that the language teachers and students in a local secondary school had rather similar positive attitudes towards the functions of code-switching. Yao (2011) realised that the functions of code-switching could vary according to the socio-environmental factors. For example, the students that she recruited in the study were from the senior year classes. She realised that the teachers reportedly rarely code-switched to the first language, Chinese, to discipline the students. She concluded that code-switching could be influenced by the age of the students.

\section{Socio-Environmental Factors Impacting on Teachers' Attitudes towards Classroom Code-Switching}

To date, the causes and effects of code-switching in ESL classrooms have been mainly investigated at the submicro level by using ethnography, discourse analysis and classroom observation methodological approaches (Lin, 2013). A common constraint of these research designs is the lack of objectivity in explaining the socioenvironmental causes of classroom code-switching. Since most previous studies were done and interpreted within highly localised classroom contexts, the impacts of socio-environmental factors, such as teachers' gender, teaching experience, qualification and ethnicity, on classroom code-switching could only be assumed or predicted, but few were actually proven or tested. This study was designed to fill this gap by focusing on the impact of the larger macro-level socio-environmental factors on teachers' attitudes towards code-switching in ESL classes. This study focused on teachers' attitudes based on the notion that attitudes are closely related to behaviours (Ajzen, 2011). Teachers' attitude towards classroom code-switching is viewed as the teachers' mental states towards classroom code-switching. Their code-switching is organised through their personal experience of teaching in the ESL classrooms, and exerts a direct or dynamic influence on the teachers' codeswitching behaviours in the classrooms (adapted from the definition of attitude proposed by Allport, 1967).

Several socio-environmental factors could impact on the teachers' attitudes towards code-switching in the ESL classroom, including language policy, the learners' characteristics, the teachers' characteristics and school contexts. First, the diversity of language policy across nations is salient. In Singapore and South Africa, the relatively strong monolingual policy in English teaching is advocated (Probyn, 2009; Vaish, 2012). Yet, the English program is differentiated by being an "immersion program" which focused on the enrichment of the children's language abilities and culture via the medium of a second language (e.g., Vaish, 2012) and a "submersion program" in which the "swim or sink" water metaphor (Baker, 1993) is adopted. In the submersion program, minimal appreciation is given to the first language, usually due to its reduced status as a minority language or a low-variety language (e.g., Breton-Carbonneau et al., 2012; Probyn, 2009). Therefore, in such 
contexts, the use of home language in the ESL classrooms is in large prohibited or regarded as reflection of low language proficiency. The type of bilingualism which submersion programs sought to produce is subtractive bilingualism (Romaine, 1997; Skutnabb-Kangas, 1984).

In contrast, the use of the home language is relatively more permissive in countries that implement immersion English programs. For example, Malaysia is a country which promotes a bi- and multilingual policy in education (Ales, 2006). Though the use of home language in English teaching is not explicitly encouraged, there is no written policy which dictates against it. Such a program sought to produce additive bilingualism (Romaine, 1997; Skutnabb-Kangas, 1984). Hence, teachers' attitudes towards code-switching are inevitably influenced by the language policy that is in place, which has close connections with the political, economical and social statuses of the languages in use.

Second, the linguistic profiles of the learners are largely different. The difference could be seen in the number and type of their home languages. In monolingual societies such as Japan and China, a large majority of the learners are only exposed to a single language in their community. The learning of a second language could involve more effort by them as compared to students who are brought up in multilingual societies, such as the English learners in Singapore, Malaysia, Brunei and South Africa. In this regard, the use of home language in teaching English has been linked to whether the teachers are tapping on home language as supporting or transitional aids or the teachers are hindering the students' potentials in learning English by violating the "swim or sink" rule (Baker, 1993).

Again, this is linked to the notions of additive and subtractive bilingualism described earlier (Romaine, 1997; Skutnabb-Kangas, 1984). According to the threshold hypothesis proposed by Cummins (1979), the relative dominance of first and second language could dictate the effectiveness of using the first language to promote the second language. Additive bilingualism could only be achieved when the proficiency levels of both languages are high (Cummins, 1979). In that case, the first language would be used to augment the learning of the second language, without imposing risks on the acquisition of both languages. However, when the levels of both languages are imbalanced or low, there might be the risks of having no or negative cognitive effects of using the first language in the teaching of second language. In the worst scenario, semilingualism is produced (Cummins, 1979). Therefore, it is possible that teachers have differential attitudes towards classroom code-switching according to their perceived knowledge of their students' language profiles and abilities. Besides that, another area which is minimally explored in the field is the comparison of teachers' and students' language profiles. The associated disparities might lead to different rationales and reasons for the ESL teachers to use or not to use the home language with the students in ESL classrooms. 
Third, teachers' characteristics are diverse. Research has shown that teachers' attitudes towards classroom code-switching are dependent on their teaching experience, training background, their faithfulness to language policy and their beliefs in the functions of classroom code-switching (Vaish, 2012). The teachers could also be different in their teaching philosophies and pedagogical preferences (de la Campa and Nassaji, 2009). In a comparative study, de la Campa and Nassaji (2009) found that the novice teacher in their study used significantly more first language for translation and administrative instruction purposes compared to the experienced teacher who used more of the first language for making personal comment and to portray his image as a bilingual speaker. Besides that, teachers might also have different competency levels in the second language which lead to them reacting differently to students with different language proficiency levels (de la Campa and Nassaji, 2009; Kang, 2013). In a Korean study, the EFL teacher with higher English proficiency was found to use more English than the first language in class, while her counterpart who was less proficient in English was found to use more first language, particularly when she was with students from lower socioeconomic levels (Kang, 2013).

As a whole, evidence shows that various types of teachers' factors influence their attitudes towards classroom code-switching and also their actual practices. Hence, it is almost impossible to expect all teachers to have similar attitudes towards code-switching in ESL contexts due to individual variations. Yet, it is important to know whether there are consistent patterns in how teachers perceive and react to classroom code-switching. For example, as previously mentioned (Ferguson, 2006; 2009; Lin, 2013), classroom code-switching was predominantly used by the teachers for functions related to helping their students to understand the lesson content, to build rapport with the students or for the purpose of maintaining classroom discipline. However, few studies had thoroughly explored the complex interplay of these multiple factors in explaining the teachers' attitudes towards classroom code-switching.

Fourth, the school contexts are also different. Studies on classroom codeswitching have been conducted in both urban and rural areas. In metropolitan cities such as Singapore and Quebec, the schools are attended by students from a diverse range of immigrant families (Breton-Carbonneau et al., 2012; Vaish, 2012). The teachers face the demands to address the differential needs of the students in relation to their readiness to perform in ESL classes. In contrast, schools in urban areas typically consist of homogeneous groups of students (Probyn, 2009). However, the teachers face a different set of challenges in ESL teaching, in relation to the lack of resources, culture and language mismatch with the students, as well as lack of community support for the students to reinforce their learning of English beyond the classroom (Probyn, 2009). Some teachers had therefore reported positive attitudes on classroom code-switching as it was seen as the only means 
to explain the teaching content to the students; while other teachers were wary of whether or not classroom code-switching could further lessen the opportunities of these students to hear standard English (Chimbutane, 2013; Probyn, 2009).

\section{ESL Learning in Malaysia}

Malaysia is a post-colonial country where English has remained as a compulsory content subject in all school types since its declaration of independence in 1957. Being a multilingual and multicultural society, the community members are diverse types of bi- and multilinguals where they could have up to two to five languages in their language repertoires (Low, Nicholas and Wales, 2010). Malaysia is one of the few countries in the world where the vernacular languages are not only preserved by the heterogeneously mixed communities at the communicative levels but also in formal education (Ales, 2006). Malaysia has a linguistically diversified education system which incorporates national schools that abide to the Malay-English bilingual policy and national-type schools that abide to a trilingual policy, namely Chinese vernacular schools (Malay-English-Mandarin) and Tamil vernacular schools (Malay-English-Tamil) (Ales, 2006). English is taught as a second language (ESL) in all school types from primary to secondary schools. The heterogeneity and plurality of bi- and multilingualism in Malaysian schools offer an opportunity to carefully consider a range of socio-environmental factors that could influence teachers' attitudes towards classroom code-switching.

Past research in Malaysia has shown that code-switching was often used as a pedagogical approach in teaching English and other content subjects (e.g., Badrul Hisham and Kamaruzaman, 2009; Kamisah and Misyana Susanti, 2011). In studies which involved lecturers and university students in Malaysia, Badrul Hisham and Kamaruzaman (2009), and Kamisah and Misyana Susanti (2011) found that most lecturers reportedly code-switched between English and the Malay language in their lectures. The lecturers predominantly felt that code-switching was instrumental in helping the students to understand the lecture content (Kamisah and Misyana Susanti, 2011). The students reported that their lecturers were code-switching to their first language for checking their understanding, explaining the meanings of new words, and explaining the grammatical aspects of test items (Badrul Hisham and Kamaruzaman, 2009). However, the students' attitudes towards classroom code-switching varied (Badrul Hisham and Kamaruzaman, 2009; Kamisah and Misyana Susanti, 2011). Specifically, students with better English proficiency were found to feel discouraged with classroom code-switching as they felt that this practice by their lecturers did not help them to improve their linguistic competencies in English. Considering that most published studies reflected the context of tertiary education, it is uncertain whether or not a similar condition applies to the primary and secondary education contexts in Malaysia. 


\section{Aim and Research Questions}

It can be summed from the literature that multiple socio-environmental factors could lead to classroom code-switching. However, most studies have been qualitative studies which only drilled students to investigate the effects of highly specific localised contexts in producing different practices and attitudes on classroom code-switching. Few studies have explored the interaction of socio-environmental factors such as school contexts and teacher characteristics in producing and predicting classroom code-switching, particularly in rural areas where the need for classroom code-switching is predicted to be higher (Probyn, 2009). Thus, in this study, the investigation of classroom code-switching was approached from a wider socio-environmental angle in order to address the following research questions:

1. What are the teachers' attitudes towards classroom code-switching in the ESL classrooms of rural schools?

2. What are the dominant socio-environmental predictors that influence the teachers' attitudes towards classroom code-switching in the ESL classrooms of rural schools?

\section{METHODOLOGY}

\section{Sampling}

This study was conducted in a rural district of Northern Peninsular Malaysia, known as Kerian. From the data file provided by the District Education Office, there are 43 national schools (30 Grade A, 13 Grade B) and 10 national-type Chinese schools (6 Grade A, 4 Grade B). As previously mentioned, national schools are schools which use Malay as the instructional language, while national-type Chinese or Tamil schools are schools which use the vernacular languages, namely Mandarin or Tamil language, respectively as the instructional language in school. Grade A and Grade B schools are the terms used to differentiate the size of schools. Grade A schools are schools with 500 students and above, while Grade B schools are with students less than 500. A purposive stratified sampling method was used to collect data from 12 schools selected from the data file provided by the District Education Office. Four categories of schools were selected, namely three Grade A national schools, three Grade B national schools, three Grade A national-type (Chinese) schools and three Grade B national-type (Chinese) schools. All teachers in the selected schools $(\mathrm{N}=62)$ were invited to participate in this survey with permission obtained from the Education District Office and the school authorities. 


\section{Questionnaire}

The questionnaire used in this study consisted of three sections: demographic information, beliefs in code-switching and attitudes towards classroom codeswitching. To address the research questions in this paper, only the data from the demographic and attitude sections were extracted for the analyses.

The demographic section included the demographic information of the samples and the school and classroom types they served. This section was divided into two parts: six questions on teachers' factors namely gender, age, ethnicity, option (English or non-English), academic qualifications, teaching experience, and the subject(s) they taught; and another five questions on school and classroom factors namely school type, school size, class size, grade, and students' English proficiency.

The section on teachers' attitudes towards classroom code-switching was adapted from a 20-item questionnaire originally developed by Yao (2011) that was divided into four sub-sections. Since Yao's original questionnaire was developed based on the context of China, the researchers amended the original questionnaire to suit the Malaysia linguistic context. A generic phrase used in all items in Yao's (2011) questionnaire was "Teachers who switch codes from English to Chinese or from Chinese to English can..." This generic phrase was changed to "Teachers who switch codes from English to another language or from another language to English can..." The term "another language" was used in this study as Malaysia is a linguistically plural society with three dominant community languages, namely Malay language, Mandarin and Tamil language that are used by the people in the community.

In line with the original design of Yao's (2011) questionnaire, there were four sub-sections: Part 1 - Teacher's persona, Part 2 - Subject access, Part 3 Classroom management, and Part 4 - Code-switching for interpersonal relations. There were five items in each part, which produced a total of 20 items in this section. The respondents were asked to respond to the items according to a 5-point Likert Scale: 1-Strongly disagree, 2-Disagree, 3-Not sure, 4-Agree, and 5-Strongly agree. All negatively worded items were reversed prior to the analyses. The internal consistency of Section $\mathrm{C}$ was tested with Cronbach's alpha coefficient and the alpha value was $0.916(\mathrm{~N}=62)$, indicating a high internal consistency. The data collected from the questionnaire were tabulated for average means and standard deviation using a SPSS program Version 22.0. Correlation and regression analyses were also conducted using the similar program. 


\section{RESULTS}

A total of 62 teachers participated in this study. However, the test of normality for the dependent variable (namely teachers' attitudes towards classroom code-switching as measured by mean composite scores of Section $\mathrm{C}$ in the questionnaire), identified the data from four teachers as outliers and hence the data were excluded from the analysis. Examination of the new data set $(n=58)$ using the Shapiro-Wilk test for normality ( $\mathrm{SW}=.955, \mathrm{df}=58, p=105)$, skewness $(-.374)$ and kurtosis (.481) statistics provided evidence to support the assumption of normality. Hence, the data of 58 teachers were used in the subsequent analyses.

\section{Socio-Environmental Factors}

The socio-environmental factors investigated included teachers factors and school factors as shown in Tables 1 and 2 .

Table 1: Distribution of teachers' factors $(\mathrm{n}=58)$

\begin{tabular}{|c|c|c|c|}
\hline \multicolumn{2}{|c|}{ Teachers factors } & \multirow{2}{*}{$\frac{\text { Frequency }}{11}$} & \multirow{2}{*}{$\frac{\text { Percentage }}{19.0}$} \\
\hline Gender & Male & & \\
\hline & Female & 47 & 81.0 \\
\hline \multirow[t]{5}{*}{ Age } & 22-30 years old & 17 & 29.3 \\
\hline & $31-35$ years old & 12 & 20.7 \\
\hline & $36-40$ years old & 8 & 13.8 \\
\hline & $41-50$ years old & 11 & 19.0 \\
\hline & 51 and above & 10 & 17.2 \\
\hline \multirow[t]{5}{*}{ Teaching experience } & $1-5$ years & 22 & 37.9 \\
\hline & $6-10$ years & 11 & 19.0 \\
\hline & $11-15$ years & 7 & 12.1 \\
\hline & $16-20$ years & 4 & 6.9 \\
\hline & 21 years and above & 14 & 24.1 \\
\hline \multirow[t]{2}{*}{ Teacher's option } & English option & 29 & 50.0 \\
\hline & Non-English option & 29 & 50.0 \\
\hline \multirow[t]{2}{*}{ Qualifications } & Diploma & 18 & 31.0 \\
\hline & Degree & 40 & 69.0 \\
\hline \multirow{2}{*}{$\begin{array}{l}\text { Ethnicity (same ethnicity with } \\
\text { the students) }\end{array}$} & Same & 10 & 17.2 \\
\hline & Different & 48 & 82.8 \\
\hline \multirow[t]{2}{*}{ Subject(s) taught in school } & English only & 28 & 48.3 \\
\hline & English and others & 30 & 51.7 \\
\hline
\end{tabular}


The teachers' demographic data showed that the majority of the teachers were female $(81.0 \%)$ and they were relatively young $(63.8 \%$ were 40 years old and below). In terms of working experience, $56.9 \%$ of the teachers had below 10 years of teaching experience while the other $43.1 \%$ had more than 10 years of teaching experience. It is worth mentioning that 14 of the senior teachers had more than 20 years of teaching experience $(24.1 \%$ of total). Besides that, there was a balanced distribution of English option (50.0\%) and non-English option teachers (50.0\%). English-option teachers were professionally trained English teachers who graduated from TESOL or ESL programs while non-English option teachers were teachers trained in other fields but were assigned to teach English due to the decisions made by the school authorities in response to a shortage of Englishoption teachers. Of the total, $69.0 \%(\mathrm{n}=40)$ of the teachers were degree holders while the rest were college-trained. A total of $82.8 \%(n=48)$ of the teachers had similar ethnicity with the students they taught. This indicated that in most cases, the teachers in the sample had similar language and cultural backgrounds as those of the students whom they taught. Besides that, around half of the teachers were teaching other subject(s) in addition to English (51.7\%).

Table 2: Distribution of school factors $(n=58)$

\begin{tabular}{llcc}
\hline & School factors & Frequency & Percentage \\
\hline Types of school & National school & 28 & 48.3 \\
& Vernacular school & 30 & 51.7 \\
School size & Grade A (500 students and more) & 36 & 62.1 \\
& Grade B (Less than 500 students) & 22 & 37.9 \\
Class size & Small (Less than 11 students) & 6 & 10.3 \\
& Average (11-30 students) & 44 & 75.9 \\
& Big (More than 30 students) & 8 & 13.8 \\
Levels taught in school & Level 1 (Year 1-3) & 30 & 51.7 \\
& Level 2 (Year 4-6) & 28 & 48.3 \\
Teacher perceived students' & Good & 1 & 1.7 \\
English abilities & Average & 45 & 77.6 \\
& Poor & 12 & 20.7 \\
\hline
\end{tabular}

As shown in Table 2, there was a near balanced distribution of teacher groups in the types of school and the levels that they taught. The sample was represented by slightly more teachers in Grade A schools (64.5\%). The majority of the teachers taught in average-sized classes with the number of students ranging between 11 and $30(75.8 \%)$ and they perceived the English abilities of their students in general as being average $(77.4 \%)$. 


\section{Teachers' Attitudes towards Classroom Code-Switching}

In this study, teachers' attitudes towards classroom code-switching were investigated according to four aspects of classroom code-switching that were suggested by Yao (2011) in his original study (refer to Table 3). The results showed that the teachers in general had positive attitudes towards classroom code-switching as represented by a mean composite score of $3.47(S D=0.58)$. Their positive attitudes in relation to subject access were most dominant $(M=3.60, S D=0.64)$, then it was followed by interpersonal relationships $(M=3.51, S D=0.67)$, classroom management $(M=3.46, S D=0.70)$ and teachers' persona $(M=3.33, S D=0.67)$. Items with the highest mean scores were related to the functions of code-switching to clarify lesson content $(M=3.76, S D=0.78)$ and clarify task instruction $(M=3.76, S D=0.76)$. Items with the lowest mean scores were related to the risk of language pollution $(M=3.07, S D=1.07)$ and whether or not code-switching could be effectively used to request silence $(M=3.16, S D=0.97)$.

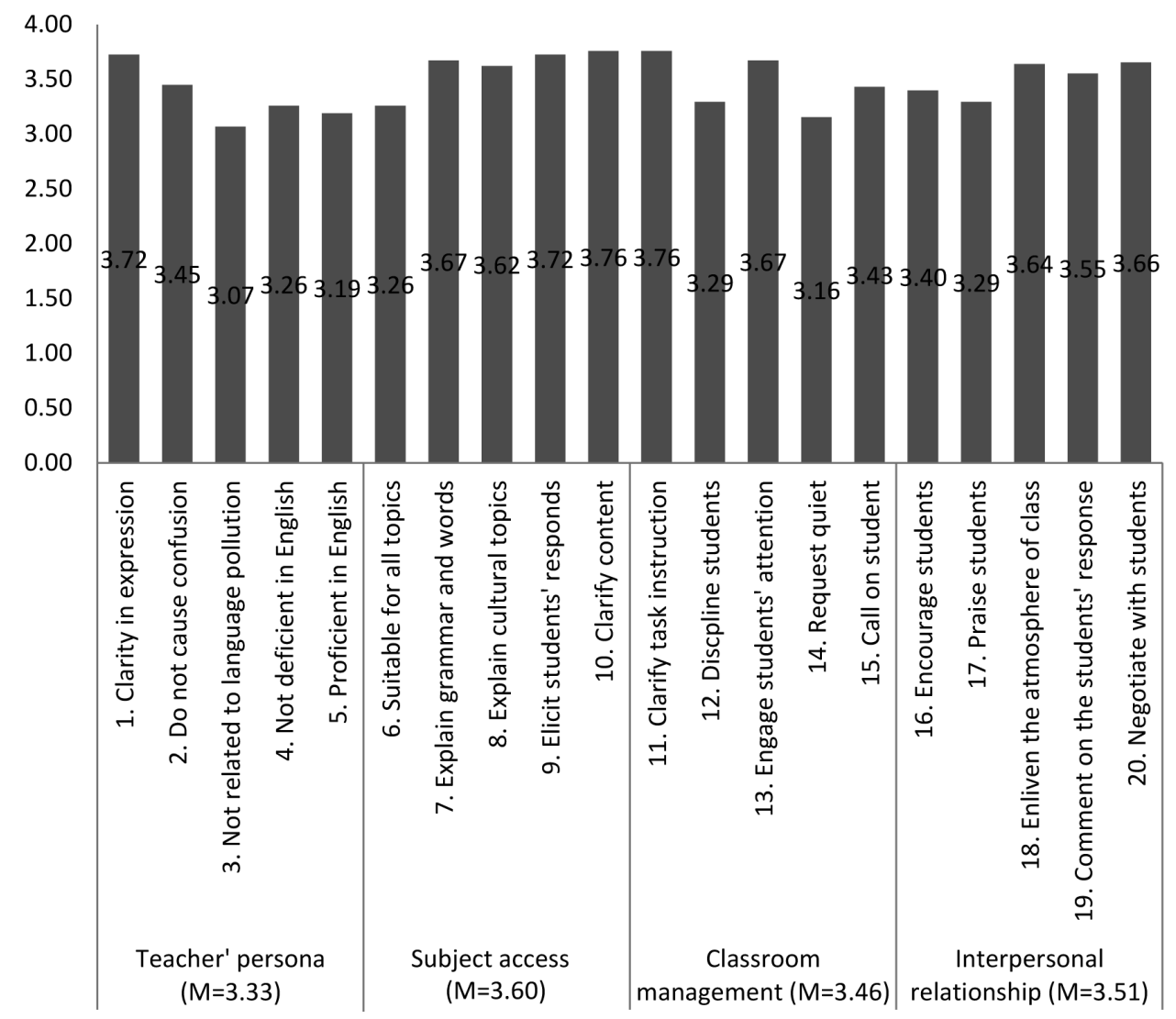

Figure 1: Mean scores of teachers' attitudes. 
Teachers' responses were split into three categories based on the 33rd and the 66th percentiles to produce three categories: (1) negative attitude (below 33 rd percentile), (2) low positive attitude (33rd-66th percentile), and (3) high positive attitude (above 66th percentile). The results are summarised in Figure 2. The results showed that around two thirds of the teachers ( $n=43$ to 45 teachers) reported positive attitudes towards subject access, classroom management and interpersonal relationships. In comparison, teachers' attitudes towards classroom code-switching in relation to teachers' persona were more disputed, with 22 teachers reporting negative attitude $(37.9 \%, \mathrm{n}=58)$ and 36 teachers reporting positive attitude $(62.0 \%, \mathrm{n}=58)$.

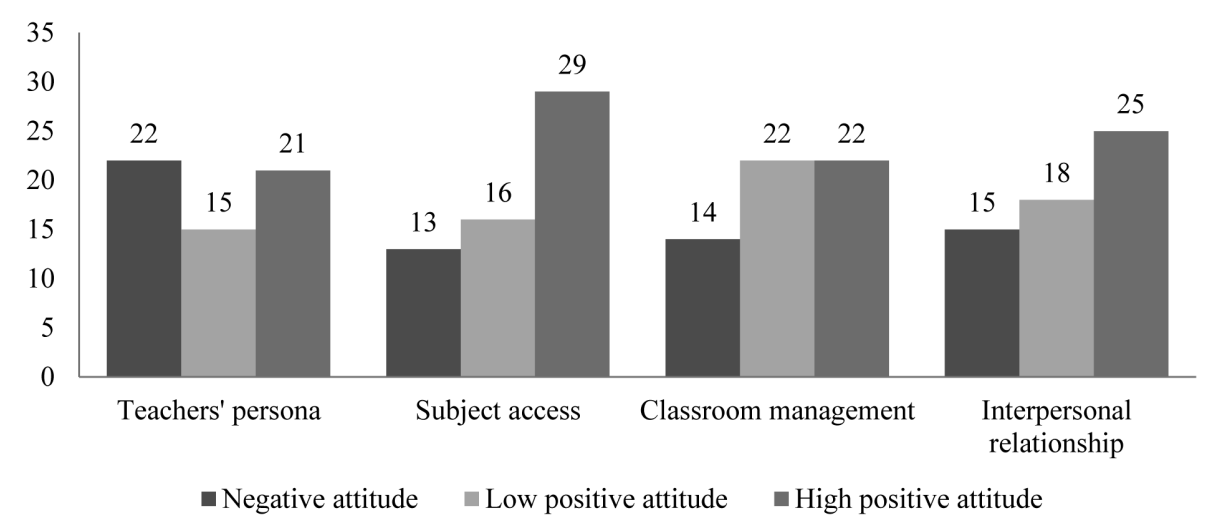

Figure 2: Distribution of teachers' attitudes in relation to four aspects of classroom code switching.

\section{Socio-Environmental Factors Affecting Teachers' Attitudes towards Classroom Code-Switching}

Correlation and regression analyses were conducted to identify predictors of teachers' attitudes towards classroom code-switching. As summarised in Table 3 , results of 1-tailed Pearson correlation analyses showed that age $[r(58)=.236$, $p<.05]$, teacher option $[r(58)=.238, p<.05]$ and teaching experience $[r(58)$ $=.341, p<.01]$ were positively correlated with teachers' attitudes in relation to teachers' persona. Class size had a significant negative correlation relationship with interpersonal relationship $[r(58)=-.233, p<.05]$. The matching of teachers and students' ethnicity had positive correlation with both classroom management $[r(58)=.225, p<.05]$ and interpersonal relationship $[r(58)=.278, p<.05]$. None of the socio-environmental factors had significant correlations with the composite mean score of attitudes. This indicated that the correlation effects observed were domain specific. In sum, the different socio-environmental factors had differential effects on the different aspects of teachers' attitudes that were investigated. 
Table 3: Pearson correlation results $(\mathrm{n}=58)$

\begin{tabular}{llccccc}
\hline & & $\begin{array}{c}\text { Teachers' } \\
\text { persona }\end{array}$ & $\begin{array}{c}\text { Subject } \\
\text { access }\end{array}$ & $\begin{array}{c}\text { Classroom } \\
\text { management }\end{array}$ & $\begin{array}{c}\text { Interpersonal } \\
\text { relationship }\end{array}$ & $\begin{array}{c}\text { Attitude } \\
\text { (Overall) }\end{array}$ \\
\hline Age & Pearson Correlation & $.236^{*}$ & .112 & -.015 & .052 & .112 \\
& Sig. (1-tailed) & .037 & .202 & .457 & .348 & .202 \\
& & & & & & $.225^{*}$ \\
Match race & Pearson Correlation & -.084 & .091 & $.278^{*}$ & .152 \\
& Sig. (1-tailed) & .266 & .248 & .045 & .017 & .128 \\
Teacher's & Pearson Correlation & $.238^{*}$ & .098 & -.060 & -.046 & .065 \\
option & Sig. (1-tailed) & .036 & .233 & .328 & .364 & .313 \\
Teaching & Pearson Correlation & $.341^{* *}$ & .094 & -.018 & .039 & .133 \\
experience & Sig. (1-tailed) & .004 & .242 & .446 & .384 & .161 \\
Class size & Pearson Correlation & -.173 & -.123 & -.108 & $-.233^{*}$ & -.187 \\
& Sig. (1-tailed) & .097 & .180 & .210 & .039 & .080 \\
\hline
\end{tabular}

"Correlation is significant at the 0.05 level (1-tailed).

${ }^{* *}$ Correlation is significant at the 0.01 level (1-tailed).

Results of regression analyses showed teaching experience was a significant predictor of teachers' attitudes towards code-switching in relation to teachers' persona $[\beta=.274, t(58)=2.29, p<.05]$. Teaching experience explained a significant proportion of variance in the teachers' persona mean scores $\left[R^{2}=.19\right.$, $F(1,58)=4.194, p<.05]$. On the other hand, the fact that whether the teachers and students were from similar cultural and linguistic backgrounds (namely same ethnicity) was a significant predictor of teachers' attitudes towards code-switching in relation to interpersonal relationships $[\beta=.468, t(58)=2.10, p<.05]$. This predictor explained a significant proportion of variance in the interpersonal relationship mean scores $\left[R^{2}=.12, F(1,58)=3.893, p<.05\right]$. Figures 3 and 4 showed the distribution of teaching experience and ethnicity factors in relation to teacher's persona and interpersonal relationships.

As shown in Figure 3, teachers with less teaching experience tended to have negative attitudes towards classroom code-switching in relation to teachers' persona while the trend shifted when the years of teaching experience increased. For teachers with more than 20 years of experience, $71.4 \%$ of the teachers in that group $(n=14)$ reported high positive attitude towards classroom code-switching in relation to teachers' persona. In strong contrast, only $22.7 \%$ of the teachers with less than 6 years of teaching experience $(n=5)$ felt the same.

As shown in Figure 4,50\% of the teachers with the same ethnicity as the students $(\mathrm{n}=24, \mathrm{~N}=48)$ reported high positive attitude towards classroom code-switching in relation to interpersonal relationships; while only $10 \%$ of the 
teachers who were not of the same ethnicity as the students $(n=1, N=10)$ reported similarly. In contrast, $40 \%$ of the teachers in the latter group had negative attitudes towards classroom code-switching in relation to interpersonal relationships $(n=4$, $\mathrm{N}=10)$.

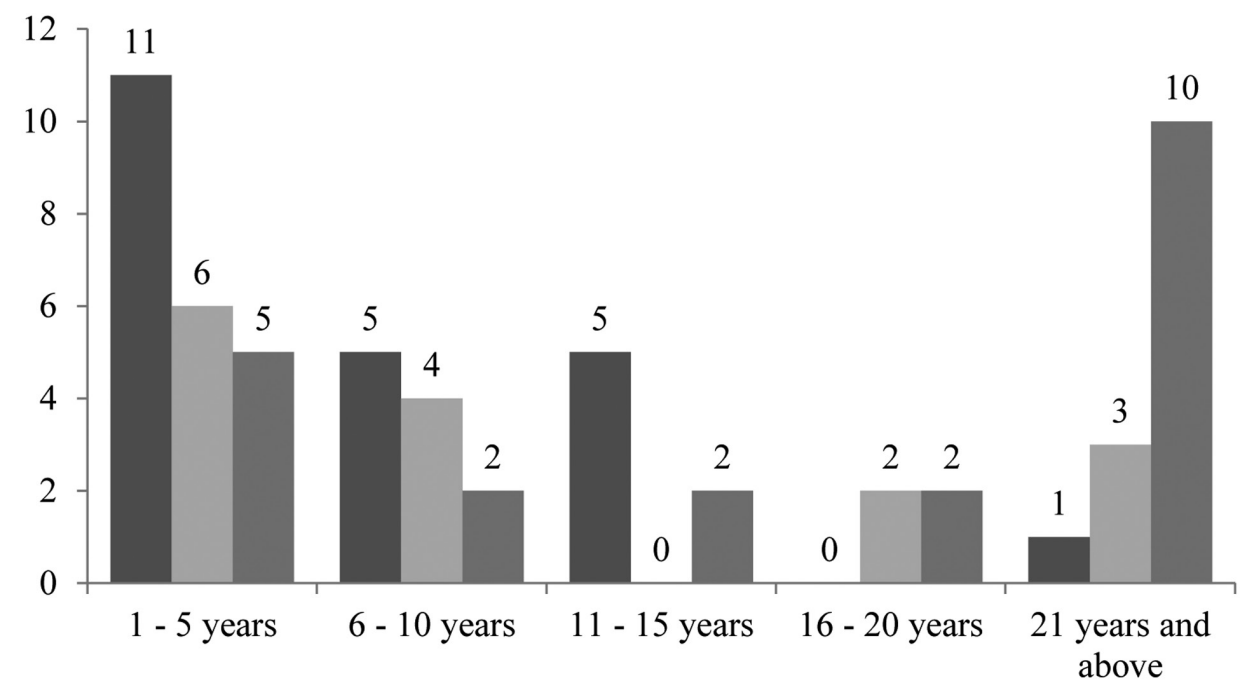

- Negative attitude $\quad$ Low positive attitude $\quad$ High positive attitude

Figure 3: Frequency of teachers' attitudes in relation to teachers' personal according to years of teaching.

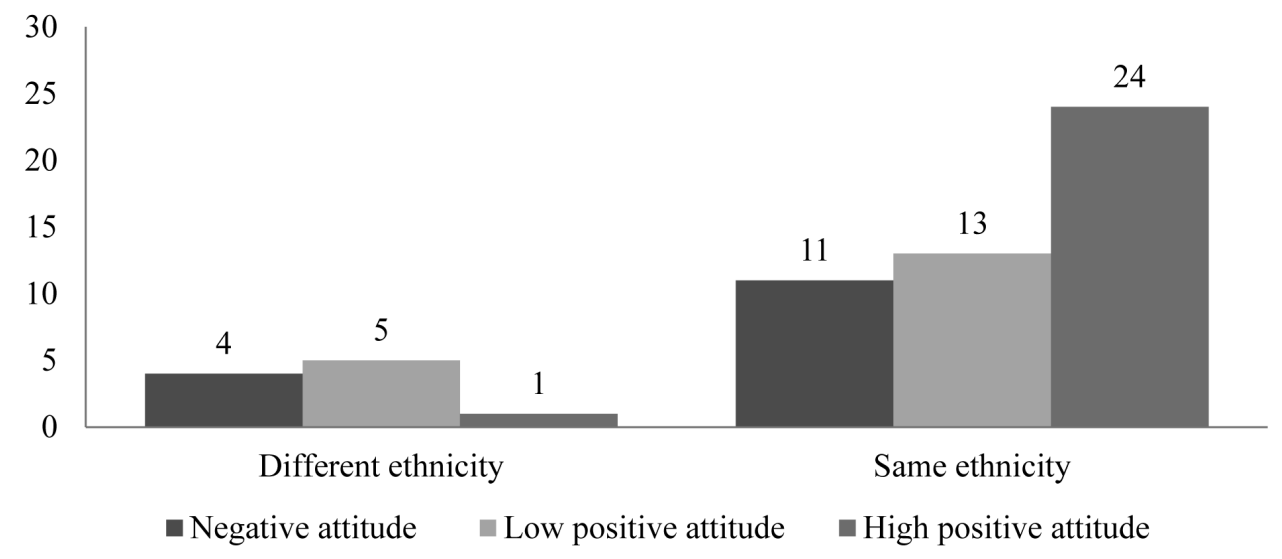

Figure 4: Frequency of teachers' attitudes in relation to interpersonal relationship according to the matching of ethnicity between teachers and students. 


\section{DISCUSSION}

This study investigated the effects of socio-environmental factors, which include a variety of teachers, school and class factors on teachers' attitudes towards classroom code-switching. The study involved a heterogeneous group of teachers who taught in a variety of school types in a rural district in Malaysia. In general, the teachers reported positive attitudes towards classroom code-switching. This finding supports the current additive bilingualism view in classroom code-switching. In immersive and additive views of bilingualism (Cummins, 1979; Romaine, 1997), classroom code-switching is regarded as a means or tool to reduce cognitive loads by utilising a person's existing linguistic resource to advance the learning of a second language. In the context of ESL classrooms, researchers such as McMillan and Rivers (2011) consider that the use of first language in the classrooms can become a "conversational lubricant" (p. 258) to promote the learning of English.

In general, the teachers reported positive attitudes to the functions of classroom code-switching which were in line with the conceptualisation of classroom code-switching as put forward by Ferguson (2006; 2009). Specifically, the teachers in the present study primarily reported positive attitudes towards code-switching in relation to subject access. In other words, the instructional and pedagogical values of code-switching were most highly perceived by these teachers as compared to other less formal functions such as the functions of interpersonal relationship and classroom management. In comparison, the average mean score for teachers' attitudes in response to the link between code-switching practices and teachers' persona was the lowest. Therefore, as evident in this study, the teachers seemed to relate more to the formal pedagogical functions of classroom codeswitching than the interactive and communicative factors.

The above findings were in contrast to the findings in a South African study (Probyn, 2009) in which the teachers reported the use of code-switching mainly for affective reasons rather than to address cognitive needs. The differences could be related to the differences in language policies, language attitudes and language statuses. In South Africa, English was adopted as the only medium of instruction in most schools. The vernacular language, namely Xhosa in Probyn's (2009) had distinctly lower status. Therefore, the teachers did not feel that the language was adequate enough to explain lesson context due to its narrow vocabulary set. Xhosa was regarded as useful mainly for the purpose of attracting students' attention and for classroom discipline, the aspects which were less prioritised by the teachers in current study. Similarly, in Yao's (2011) study which involved secondary school EFL teachers in mainland China, the teachers rarely switched to Mandarin for affective purposes. Yao (2011) related the phenomena to the fact that the teachers were senior-class teachers and hence possibly they adopted a more formal teaching style. The varieties of teachers' reported attitudes towards the functions of code- 
switching showed that the attitudes were highly contextually dependent based on the complex interplay of socio-environmental factors that were in place.

The results showed that teaching experience was a significant predictor of teachers' attitudes towards code-switching in relation to teacher's persona. It may be concluded that the senior teachers tended to have more positive attitudes that code-switching had positive effects on teachers' image. The findings provided alternative quantitative evidence to support previous available qualitative evidence that was found by Vaish (2012) which involved a sample of Singaporean preschool teachers. One possibility was that senior teachers were more confident than the junior teachers with their instructional competency and English language proficiency. Hence, they did not perceive the use of code-switching as a manifestation of language deficiency or teachers' weakness. The fact that the senior teachers reported positive attitudes towards classroom code-switching provides an insight that classroom code-switching has been proven to be a good thing from their extensive years of teaching. In the previous studies, senior ESL teachers were also found to have more positive attitudes towards classroom codeswitching as compared to their younger colleagues (Vaish, 2012). However, most findings were about senior teachers' beliefs that home language could be used as an instructional tool, while less was related to its positive effects on teachers' image. Hence, the findings from the current study added to the views on the positive effects of classroom code-switching.

Another unique finding contributed by the current study was that the homogeneity of ethnicity had an effect on teachers' attitudes towards classroom code-switching, particularly in relation to rapport building and to reduce distance between the teachers and students. The findings suggested that the positive attitudes were more prominent when the teachers and students shared the same language and cultural backgrounds, but not otherwise. One possible reason was that the ability to employ code-switching required competency in the language(s) that were in use. The items about the interpersonal relationships were about whether or not the teachers reported positive attitudes towards code-switching from English to another language to better encourage the students, enliven the class atmosphere, comment on students' responses and negotiate with students. When a teacher is not fluent in the students' first language, it would be difficult for the teachers to effectively provide feedback and negotiate with the students. Naturally, in this instance, the teacher would continue to use English which is the mutual language that connects him or her to the students. Similarly, the acts of praising and enlivening the classroom atmosphere would require one to have adequate vocabulary and appreciation of the language(s) in use. In this instance, it is also natural for the teacher to not use a language which he or she is not familiar with. Further, the use of language to reduce distance also involves a certain level of cultural appreciation. When the teacher is not the native speaker of the students' 
first language, it might not be appropriate for the teacher to actually tell a joke using the students' first language, which might be risky as it could be considered as culturally insensitive and offensive.

The findings from this study provided important insights that teaching experience and the language/culture repertoire of the teachers are significant factors that predict teachers' attitudes towards code-switching in two different dimensions, namely in relation to teachers' persona and interpersonal relationships. Therefore, causes and effects of teachers' attitudes towards classroom code-switching are multidimensional and should not be superficially interpreted. Though it is possible that teaching experience and language repertoire of the teachers are salient predictors that remain constant in most bi- and multilingual classroom settings, it is important to note that the findings were produced from analyses of the specific sets of factor interplays which defined the background of this study. In other contexts, the relative importance of teaching experience and teachers' language/cultural background might increase or decrease in reaction to the type of bi- and multilingual classes they are teaching. For example, when an ESL teacher is teaching in a class with very low English-proficiency students, the effect of teaching experience might be minimal. In such a context, regardless of their teaching experience, the teachers might be less wary of the effect of employing code-switching on their teachers' persona as compared to when they are teaching a class of high-achieving students.

Therefore, the study faced the same constraints as in other studies on classroom code-switching. First, the interpretation and generalisation of results can only be done in reference to the study background. However, a novelty attempted in this study was that a larger socio-environmental context was being considered (12 schools, 2 school types, 2 school sizes and 58 teachers) as compared to many conventional studies in classroom code-switching which only focused on a single classroom or specific school context. Therefore, the findings of this study offer a better overview of classroom code-switching than what were previously attained in conventional ethnography studies. The second limitation of this study is related to its reliance on a single research design, namely the attitudinal survey. Bi- and multilingual research has shown that bi- and multilingual speakers' perceptions of their speech might not actually reflect what they are doing in real situations. For example, when teachers reported limited use of the first language in their classes, they might in fact employ extensive code-switching which they were not consciously aware of. However, in this study, merely the teachers' perceptions were studied, i.e., their attitudes towards classroom code-switching. Hence, the findings should be representative enough since there was no instillation of recalling pressure on the teachers. Even so, future studies could consider the need to incorporate other research designs such as interviews to offer more in-depth insights on the teachers' views and for the purpose of data triangulation. 


\section{CONCLUSION}

In line with the current additive bilingualism view in classroom code-switching, the teachers in this study reported positive attitudes towards classroom codeswitching in relation to teachers' persona, subject access, classroom management and interpersonal relationships. Their reported attitudes towards classroom codeswitching in relation to teachers' persona and interpersonal relationships were found to be influenced by their teaching experience and language/culture backgrounds. The findings illustrated an interplay of socio-environmental factors impacting on teachers' attitudes towards classroom code-switching based on the contextual situations experienced by ESL teachers in primary schools in a rural district of Malaysia. Duplication of research in other socio-cultural contexts is recommended to further examine the constant effects of sociolinguistic relationships that were identified.

\section{ACKNOWLEDGEMENTS}

This study was supported by Fundamental Research Grant Scheme (203/ PGURU/671443).

\section{REFERENCES}

Ajzen, I. 2011. The theory of planned behaviour: Reactions and reflections. Psychology and Health 26(9): 1113-1127. https://doi.org/10.1080/08870446.2011.613995.

Ales Puteh. 2006. Language and nation building: A study of the language medium policy in Malaysia. Petaling Jaya, Malaysia: Strategic Information and Research Development Centre.

Allport, F. W. 1967. Attitudes. In Readings in attitude theory and measurement, ed. M. Fishbein, 1-13. New York, NY: John Wiley and Son, Inc.

Alvarez-Caccamo, C. 2001. Codes. In Key terms in language and culture, ed. A. Durant. Oxford, UK: Blackwell.

Auer, P. 1999. From code-switching via language mixing to fused lects toward a dynamic typology of bilingual speech. International Journal of Bilingualism 3(4): 309332. https://doi.org/10.1177/13670069990030040101.

Badrul Hisham Ahmad and Kamaruzaman Jusoff. 2009. Teachers' code-switching in classroom instructions for low English proficient learners. English Language Teaching 2(2): 49-55. https://doi.org/10.5539/elt.v2n2p49.

Baker, C. 1993. Foundations of bilingual education and bilingualism. Clevedon: Multilingual Matters. 
Breton-Carbonneau, G., A. Cleghorn, R. Evans and D. Pesco. 2012. Pedagogical and political encounters in linguistically and culturally diverse primary classrooms: Examples from Quebec, Canada, and Gauteng, South Africa. Compare: A Journal of Comparative and International Education 42(3): 373-391. https://doi.org/10.1 080/03057925.2011.650870.

Chimbutane, F. 2013. Codeswitching in L1 and L2 learning contexts: Insights from a study of teacher beliefs and practices in Mozambican bilingual education programmes. Language and Education 27(4): 314-328. https://doi.org/10.1080/09500782.201 3.788022 .

Creese, A. and A. Blackledge. 2010. Translanguaging in the bilingual classroom: A pedagogy for learning and teaching. The Modern Language Journal 94(1): 103115. https://doi.org/10.1111/j.1540-4781.2009.00986.x.

Cummins, J. 1979. Linguistic interdependence and the educational development of bilingual children. Review of Educational Research 49: 222-251. https://doi. org/10.3102/00346543049002222.

de la Campa, J. C. and H. Nassaji. 2009. The amount, purpose, and reasons for using L1 in L2 classrooms. Foreign Language Annals 42(4): 742-759. https://doi. org/10.1111/j.1944-9720.2009.01052.x.

Ferguson, G. 2009. What next? Towards an agenda for classroom codeswitching research. International Journal of Bilingual Education and Bilingualism 12(2): 231-241. https://doi.org/10.1080/13670050802153236.

. 2006. Language planning and education. Edinburgh: Edinburgh University Press.

Ghobadi, M. and H. Ghasemi. 2015. Promises and obstacles of L1 use in language classrooms: A state-of-the-art review. English Language Teaching 8(11): 245254. https://doi.org/10.5539/elt.v8n11p245.

Halliday, M. A. K. 1978. Language as social semiotic. London: Arnold.

Holmes, J. 2001. An introduction to sociolinguistics. Kuala Lumpur: Pearson Education Limited.

Joyce, P. 2015. L2 vocabulary learning and testing: The use of L1 translation versus L2 definition. The Language Learning Journal May: 1-12. http://dx.doi.org/10.1080 /09571736.2015.1028088.

Kamisah Ariffin and Misyana Susanti Husin 2011. Code-switching and code-mixing of English and Bahasa Malaysia in content-based classrooms: Frequency and attitudes. The Linguistics Journal 5(1): 220-247.

Kang, D.-M. 2013. EFL teachers' language use for classroom discipline: A look at complex interplay of variables. System 41(1): 149-163. https://doi.org/10.1016/j. system.2013.01.002.

Lin, A. 2013. Classroom code-switching: Three decades of research. Applied Linguistics Review 4(1): 195-218. https://doi.org/10.1515/applirev-2013-0009.

Low, H. M., H. Nicholas and R. Wales. 2010. A sociolinguistic profile of 100 mothers from middle to upper-middle socio-economic backgrounds in Penang-Chinese community: What languages do they speak at home with their children? Journal of Multilingual and Multicultural Development 31(6): 569-584. https://doi.org/1 0.1080/01434632.2010.527342. 
McMillan, B. A. and D. J. Rivers. 2011. The practice of policy: Teacher attitudes toward "English only". System 39: 251-263.https://doi.org/10.1016/j.system.2011.04.011.

Michael-Luna, S. and S. Canagarajah. 2008. Multilingual academic literacies: Pedagogical foundations for code meshing in primary and higher education. Journal of Applied Linguistics 4(1): 55-77.

Milroy, L. and P. Muysken. 1995. One speaker, two languages: Cross-disciplinary perspectives on code-switching. Cambridge, UK: Cambridge University Press. https://doi.org/10.1017/CBO9780511620867.

Palmer, D. K., R. A. Martínez, S. G. Mateus and K. Henderson. 2014. Reframing the debate on language separation: Toward a vision for translanguaging pedagogies in the dual language classroom. The Modern Language Journal 98(3): 757-772. https://doi.org/10.1111/modl.12121.

Pfaff, C. W. 1979. Constraints on language mixing: Intrasentential code-switching and borrowing in Spanish/English. Language 291-318. https://doi. org/10.2307/412586.

Poplack. 1980. Sometimes I'll start a sentence in English y termino en espanol: Towards a typology of code-switching. Linguistics 18: 581-618. https://doi.org/10.1515/ ling.1980.18.7-8.581.

Probyn, M. 2009. Smuggling the vernacular into the classroom: Conflicts and tensions in classroom codeswitching in township/rural schools in South Africa. International Journal of Bilingual Education and Bilingualism 12(2): 123-136. https://doi. org/10.1080/13670050802153137.

Ramachandran, S. D. and H. Abdul Rahim. 2004. Meaning recall and retention: The impact of the translation method on elementary level learners' vocabulary learning. RELC 35(2): 161-178. https://doi.org/10.1177/003368820403500205.

Romaine, S. 1997. Bilingualism. Oxford: Blackwell Publishers.

Sali, P. 2014. An analysis of the teachers' use of L1 in Turkish EFL classrooms. System 42: 308-318. https://doi.org/10.1016/j.system.2013.12.021.

Skutnabb-Kangas, T. 1984. Bilingualism or not: The education of minorities. Clevedon: Multilingual Matters.

Vaish, V. 2012. Teacher beliefs regarding bilingualism in an English medium reading program. International Journal of Bilingual Education and Bilingualism 15(1): 53-69. https://doi.org/10.1080/13670050.2011.594496.

Yao, M. 2011. On attitudes to teachers' code-switching in EFL classes. World Journal of English Language 1(1): 19-28. https://doi.org/10.5430/wjel.v1n1p19. 
